\title{
Joint ringing efforts to unravel complex migratory patterns across ecological barriers: the potential of networking
}

Fernando Spina, Istituto Superiore per la Protezione e la Ricerca Ambientale, Via Cà Fornacetta, 9, I-40064 Ozzano Emilia (BO); email fernando.spina@isprambiente.it

\begin{abstract}
Ecological barriers represent a challenging and potentially risky component of migratory flyways. Complex patterns involve large arrays of species and huge numbers of birds in crossing deserts, mountain chains and large stretches of sea. Despite the fast recent developments of new marking technologies, standardised ringing applied to networks of stations widely distributed across the barriers still represents a unique tool to unravel different aspects of the progression of the waves of migration. The Italian Ringing Centre at ISPRA co-ordinates two major projects referred, respectively, to songbird migration across the Mediterranean in spring and over the Alps in autumn. Networks of ringing stations provide details on geographical distribution of flyways based on first-capture data and on species-specific seasonality of movements as explained also by ecological factors acting both on the wintering and breeding grounds. Physical conditions of migrants at different stages of barrier crossing provide details on the energetic cost of endurance flights, contributing to the understanding of the ecological needs of migrants. Conditions of staging migrants, stopover duration and habitat use by migrants significantly contribute to the understanding of time- vs risk-minimizing strategies, within the general framework of the energetic balance of migration. Also networks represented by the national communities of ringers contribute to the understanding of the ecological role a given country plays within larger migratory flyways. Ringing still offers a great potential to analyse existing large-scale and long-term datasets also to provide a sound scientific basis for the conservation of migrants.
\end{abstract}

\section{Introduction}

Migration may imply significant mortality risks (Sillet and Holmes 2002, but see Newton 1998 for a general review of mass mortality of migrants); during prolonged migratory flights, the crossing of extended ecological barriers (e.g., mountain chains, deserts, seas and oceans) entails endurance flights which require large amounts of energy, potential challenges for orientation and drift-compensation. Adverse weather conditions can also imply mass mortality in migrants. Within the Palaearctic-African migration system, the Sahara desert, the Mediterranean Sea and the Alps represent important ecological barriers for migrants.

During the crossing of barriers (Bairlein 1992, Biebach 1990, Gill et al. 2005, Nisbet et al. 1963), when time spent in active flight is often the longest, it is particularly hard to monitor movement patterns; however, given the challenges and risks related to barrier crossing, it is important to understand the needs migrants have during these particularly demanding phases of their journeys.

Modern technologies allow continuous and accurate tracking of birds during prolonged flights (e.g., through satellite tracking, Gill et al. 2005). While till few years ago it was still 
hard to apply new technologies (like satellite telemetry or geo-locators) to large numbers of small-sized migrants, most promising results recently originated from relevant pilot studies, which might soon open the door to a new era for tracking migratory pathways (Stutchbury et al 2009, Bächler et al. 2010, Stutchbury et al. 2010, Bairlein et al. 2011, Schmaljohann et al. 2011). However, traditional ringing methods still maintain their values, given also they allow to collect important variables for the understanding of the progression of migrants along flyways like, e.g., details on physical conditions of birds; also, networks of ringing stations working at the same time and using the same protocols across large geographical areas offer unique opportunities to unravel complex migratory patterns across barriers (Busse \& Kania 1970, Berthold \& Schlenker 1975, Dolnik 1990, Berthold et al. 1991, Bairlein 1995, 1997, Spina et al. 1997, Bairlein 1998, Schaub \& Jenni 2000, Schaub \& Jenni 2001, Bairlein 2004).

Since over 20 years the Italian Ringing Centre at ISPRA has launched and co-ordinated large-scale and long-term migration studies based on networks of ringing sites (Spina et al. 1997, Pedrini et al. 2008). The two largest projects refer to spring and autumn migration, respectively: in spring, migrants originating from African winter quarters, and which have in many cases already overcome the Sahara desert, are studied during their crossing of the barrier represented by the Mediterranean through the Progetto Piccole Isole (Mediterranean islands project, PPI), while autumn movements across the Alps by a large array of species of both intra-Palaearctic and trans-Saharan migrants are monitored through the Progetto Alpi (Alps Project, PA, fig. 1).

General seasonal and daily patterns of movements across the barriers are studied in each of the projects' ringing stations, while more detailed satellite projects are carried out at specific sites, in order to get a more in-depth understanding of the mechanisms governing flight and stopover patterns.

Given the important role of staging sites played by islands and coastal habitats in concentrating large numbers of migrants, the scope of the networks of ringing stations is to provide a sound scientific basis for regional conservation policies. This is particularly true for the problems faced by migrants crossing the Mediterranean. The whole basin represents a geographical area characterized by an intense use of birds as food since ancient times through trapping and liming and, still nowadays, as a target for sport hunting (Woldhek 1980, Hepburn 1985, Fenech 1992); both the northern and, more recently, the southern coasts of the basin represent the main tourist destination in the world, with a tendency to a further increase in numbers (Hoballah 1996). Across the Alps specific valleys and high passes need being protected from hunting and habitat loss, fragmentation or degradation caused by increasing housing or infrastructures like sky resorts or wind farming.

Here I will review the different types of information which can be obtained through these networks of standardised ringing sites and discuss the potential of such large-scale projects for site and species conservation.

\section{Materials and methods}

Aside to standardised ringing protocols (Bairlein 1995), different methods have been used to collect specific variables for the various related satellite projects on migration ecology, 
behaviour and physiology. For details and references on data collection and analyses, see the single papers referred to below.

\section{Description of migratory routes.}

Ringing recoveries still nowadays represent the main source of information on migratory routes at the species and population level for most bird species. Nevertheless, recovery probabilities are generally low or very low for a large number of species, and especially so for small-sized songbirds which are not hunted.

Networks of ringing sites may provide a useful contribution to the description of migratory routes by using first-capture data. If considering groups of species with broadly similar habitat requirements, the relative frequency of individual species within a larger selected array of taxa across networks of ringing sites may produce interesting geographical patterns of frequency of given species, throwing light on their migratory routes. In a pilot study originated from the PPI, Pilastro et al. (1987) for the first time used this method to describe spring routes across the Western and Central Mediterranean for species like Melodious $H$. polyglotta and Icterine $H$. icterina Warblers (fig. 2). Such patterns along a longitudinal gradient may show cases of migratory "detours" (Alerstam 2001) even during spring migration, when time-minimization strategies (Alerstam \& Lindström1990) should imply direct routes between wintering and breeding areas.

Apart from data on spatio-temporal distribution of birds at the species level, standardised ringing activities may also shed light on intra-specific patterns, and namely indicate movements of birds of different populations across large areas. Matching the cline in size recorded with increasing longitude over the breeding quarters of the Garden Warbler Sylvia borin, progressively longer-winged and larger birds ringed in the Central vs Western Mediterranean indicate how migrants breeding progressively to the east overfly the sea in spring, regardless of the length of the stretch of sea to cross (Grattarola et al. 1999, fig. 3). Similar patterns have also been recorded out of a larger data set for Garden Warbler and also in Common Whitethroat $S$. communis, another species which is well represented all across the range of PPI network sites. Birds staging in sites at increasing longitudes are longer-winged and have a larger lean body mass (Cecere 2004); the crossing of larger stretches of sea (and desert?) while moving from the western towards the central Mediterranean is also confirmed requiring more energy, as shown by the progressively lower fat levels recorded (Cecere 2004). The frequency of these longitude-related patterns confirms time-minimization models in spring adopted by birds deciding to follow the shortest possible routes towards their breeding areas.

Networks of ringing sites across large areas may help describing patterns of presence of species as related also to different variables or features, like for instance altitude of monitoring sites across the Alps. Here, ringing sites at high altitudes above $1,400 \mathrm{~m}$ a.s.l. see a high frequency of e.g., among Finches, Bramblings Fringilla montifringilla or Siskins Carduelis spinus; on the contrary, most Greenfinches C. chloris are trapped below $700 \mathrm{~m}$ a.s.I. As for categories of migrants, an increasing frequency of trans-Saharan species is recorded at progressively higher altitudes, while the opposite is true for intra-Palaearctic ones (Pedrini et al. 2008). 


\section{Barrier crossing: speed of movements, daily flight patterns and progressive use of reserves}

Islands at increasing latitudes provide details on the speed of movements over the sea; very similar trapping patterns recorded in a wide array of species along the Tyrrhenian confirm a fast northwards progression of spring migration (Spina et al. 1993). Another fascinating aspect of barrier crossing is the pattern of movements during night and day. Also in this case, continuous and standardised ringing from dawn to dusk is a useful tool to track birds. For typical "nocturnal" migrants in spring one can hypothesise departure at dusk from areas in Africa; the scattered presence of islands and/or coastal monitoring sites at increasing latitudes across the barrier offers the opportunity to analyse the progression of the waves of migration over the sea based on hourly trapping patterns of a given species, as in the case of the Garden Warbler (Grattarola et al. 1999, fig. 4). The validity of this indication is confirmed by the related progressive decrease in conditions, as indicated by lower standardised body mass values with increasing latitude of islands. The fact that birds trapped later on a given island have been in fact flying longer before reaching the site is also confirmed by plasma concentrations of metabolites (Jenni et al. 2000).

\section{Seasonality of movements, differential migration of sex- and age-classes}

Given the fast spring movements across the sea, a low inter-annual variability is recorded in the seasonality of movements for same species and across sites along main flyways like, e.g., the Tyrrhenian (Spina et al. 1994). The species-specific seasonal patterns of passage recorded have shown that species passing earlier across the central Mediterranean have more northern breeding grounds, are cavity nesters and have larger sexual size dimorphism, while moulting wing feathers in Africa delays spring migration among Passerines (Rubolini et al. 2005).

Analyses of seasonality of passage across the Mediterranean have also confirmed differential migration of sex- and age-classes to be a general feature of spring migration (Spina et al. 1994). The large samples of species and individuals which can be investigated in sites concentrating large numbers of migrants as those represented by islands has allowed to investigate the variables explaining the uneven degree of protandry recorded across species. In dichromatic species protandry has been found to correlate with sexual dichromatism, the most dichromatic taxa showing the largest seasonal difference of passage between sexes (Rubolini et al. 2004). In a larger set of species, including monochromatic ones, protandry has been found to positively covary with sexual size dimorphism but not with dichromatism, supporting a "mate choice" model with females assessing mate quality based on condition-dependent arrival date (Saino et al. 2010). The earlier movements of adults with respect to yearlings observed in a number of species might be explained by the faster movements of the former, both based on more pointed wings in some species as well as experience, and on a strategy of avoidance of direct conflict upon settlement by later arriving yearlings with potentially dominating and earlier settling adults (Hill 1989, Spina et al. 1994).

\section{Conditions of staging migrants, stopover duration, numbers of staging migrants}


In spring, islands and coastal habitats host huge numbers of passage migrants; they represent excellent opportunities to investigate patterns of return migration towards large geographical areas. Similarly in autumn, alpine passes see large concentrations of birds. In order to better understand the role of such peculiar sites in terms of conservation of migrants it is important to understand how birds make use of these habitats. Spring migrants staging on Mediterranean islands are represented by birds in variable physical conditions. Both exhausted migrants and birds in excellent conditions come down for generally very short stopovers. The marked inter-specific differences in average physical conditions are explained by the northernmost latitude of the wintering habitats used by each species in Africa (Pilastro \& Spina 1997, fig. 5). Specific studies on stopover duration at particular sites, like the Island of Ventotene, have shown that birds which are later retrapped had worse conditions at first capture (body mass, fat score) than those which are no longer encountered; also the hour of first capture is later in birds which are retrapped (Tenan \& Spina 2010). This suggests that birds arriving on the islands earlier in the day are in better conditions and resume migration earlier than later arriving weaker migrants, which will stage longer. In general terms, stopover duration on islands during spring crossing of the Mediterranean is very short, with a tiny fraction of birds staging longer than 1 day. Stays of at least 2 days allow birds to improve their conditions, despite a very low daily mass gain. A tendency for progressively shorter stopovers later in the season as observed in some species (e.g., Garden Warbler) might be related to the generally more constant and favourable weather conditions, as well as to a progressive urgency to reach the breeding quarters before it really gets too late to nest (Tenan \& Spina 2010). Short stays duration across the Mediterranean by spring long-distance migrants has been recently investigated through whole-island telemetry on Garden Warblers, confirming brief stages, whose duration is dependent on the conditions of migrants, birds in better state staying shorter than leaner migrants (Goymann et al. 2010).

In autumn, the complex migratory system involving the alpine chain has shown intraspecific differences in conditions between valley bottoms and high passes, with lower fat scores and body mass values in birds trapped high on the passes rather than at lower altitudes. These patterns are recorded both in long-distance (e.g., Pied Flycatcher Ficedula hypoleuca) and intra-Palaearctic migrants (e.g., Robin Erithacus rubecula, Pedrini et al. 2008), suggesting higher frequencies of active migrants among birds trapped on high passes, which will have already at least partly used their energy reserves.

For conservation purposes it would be extremely important to have sound estimates of the actual number of birds staging at these crucial bottleneck sites. However, the extremely high frequency of transients within the population we monitor in these peculiar situations still nowadays represents an analytical challenge even for the most sophisticated CMR (capture-mark-recapture) models. We should hope, however, these modelling difficulties to be soon overcome or new technologies to come and allow reaching a detailed picture of the numbers of individuals relying, even if during a short but likely important part of their migratory flights, on these scattered, fragile and too often unprotected stopover sites.

\section{Habitat use during stopover}

The use birds make of the habitats at stopover sites is important to understand the reason why migrants decide to stage; this is relevant to evaluate the conservation values of these areas. In spring, time minimization theories suggest that birds should attempt to reduce the overall duration of their journey towards the breeding grounds, hence we could expect 
them to minimize stopovers. Data collected through the PPI have confirmed that also large numbers of birds in positive conditions stage on the islands, although only for short periods. Detailed studies on habitat use and physiology of staging migrants have been carried on at the island of Ventotene, later leading to a specific larger project across the network of PPI sites. Behavioural observations (Schwilch et al. 2000, Cecere et al. 2010) and physiological studies (Jenni et al. 2000, Schwilch et al. 2002) have shown that even short stopovers are of crucial importance for birds landing in variable conditions to rest, take advantage from the local food resources and restore key metabolic parameters, in order to avoid risky physiological states. A particularly interesting model has been described especially for Sylvia and Phylloscopus warblers, which make intensive use of the nectar abundantly produced by few plant species like Ferula communis and Brassica oleracea. Birds will visit the plants soon after landing on the island; the fact that nectar, which is rich in sugars, can be easily collected allows even birds with reduced digestive tracts (Schwilch et al. 2001) to uptake sugars in a very short period of time; this strategy allows migrants to restore or increase sugar levels in their blood and be able to resume migration after a very short stopover (Cecere et al. 2011). A strong behavioural plasticity of passage migrants to adopt this strategy depending on the habitat conditions they find upon landing on a given site has been described based on marked intra-specific feeding patterns recorded on islands even at very close distance (Cecere et al. 2010). A general survey across the network of PPI sites has shown that this behaviour is restricted only to few sites offering very specific conditions of pioneer vegetation which is featured by the presence of plants which are particularly suitable for nectar feeding by birds, again supporting a plastic response by migrants to local conditions and their potentially flexible diet. The fact that birds rely on nectar on Ventotene regardless of their conditions supports the advantage of this feeding strategy vs. e.g., insect hunting, most likely in terms of energy absorption and time budget. Nectar feeding by birds before their arrival on Mediterranean islands has also been described, based on the presence of pollen from African plants as well as dry pollen recorded on freshly landed birds (Cecere et al. 2010). Nectar feeding in Africa has been confirmed also through direct observation of migrants during Sahara crossing (Salewski et al. 2006). Promising experiments aimed to test possible coevolution between Mediterranean plants and birds in a potential role of pollinators might further contribute to the understanding of fascinating relationships which could be described through intense coordinated ringing activities.

\section{Networks represented by national communities of ringers}

Aside to specific projects like those outlined above, increasing networking based on ringing is realised through the national Ringing Schemes. The fast increase in the use of PCs allows nowadays an efficient management of data directly by the ringers, who can code and computerize all information they collect, directly updating the relevant national databases. The Italian Ringing Centre represents an example of routine collection of firstcapture as well as recapture and control data which are computerised by ringers, allowing a central storage of this information since 1982. Birds ringed in Italy are also routinely measured and variables on their conditions are collected (i.e., fat score, muscle score, body mass). The mass of information which is gathered offers a large potential of analyses. General statistics at the national level on seasonal patterns in relative abundance, differential migration of sex- or age-classes and average conditions provide useful hints to better understand the way a given species unrolls its annual cycle in a given country (Licheri \& Spina 2002, Spina \& Licheri 2003, Licheri \& Spina 2005). Even general trapping figures in species with similar ecological conditions during passage and stopover 
in Italy, like Collared Ficedula albicollis and Pied Flycatcher F. hypoleuca (Fig. 6), confirm clearly different seasonal patterns of presence, Collared Flycatcher being present almost exclusively in spring, during return loop movements from Eastern African wintering grounds. In long-distance migrants, like the Barn Swallow Hirundo rustica, seasonal patterns in conditions (frequency of fat birds, average body mass, figs. 7,8 ) tell much on autumn pre-migratory fattening in a country like Italy, facing the double barrier represented by the Mediterranean and Sahara. The confirmation of the importance of given countries for the preparation to migration for huge numbers of birds belonging to wide arrays of species is an important contribution to decide on habitat conservation and management policies. Similar analyses of data routinely stored at National Ringing Centres would offer unique opportunities to unravel pre-migratory and migratory patterns at the flyway scale. The community of EURING National Ringing Centres has the potential to carry on such analyses and further improve the great potential of its Data Bank also through an active management of these huge sets of first-capture data (Baillie et al. 2007).

\section{Closing remarks}

Despite having been by far the most widely used technique for bird migration studies since well over one century, ringing still represents a powerful tool to unravel complex migratory patterns for a high percentage of species. The fast growing opportunities offered by new technologies are a further stimulus to improve international networking based on ringing, as well as to analyse existing data sets originated from decades of ringing world-wide, in order to help targeting projects based on such innovative technologies

\section{Acknowledgments}

I wish to thank Prof. Franz Bairlein for inviting me to report on our network projects at the Celebration meeting for the 100 Years of Vogelwarte Halgoland. My deep appreciation and warmest thanks to the hundreds of volunteer ringers who contribute to carry on such demanding projects. The Alps Project is crucially supported by the Trento Museo delle Scienze. Results of the Progetto Piccole Isole ISPRA: paper n. 50.

\section{References}

Alerstam T (2001) Detours in bird migration. J. Theor. Biol., 194: 1-13.

Alerstam T, Lindström A (1990) Optimal bird migration: the relative importance of time, energy and safety. pp. 331-351 in Bird migration: physiology and ecophysiology (ed. E. Gwinner). Berlin, Springer Verlag.

Bächler E, Hahn S, Schaub M, Arlettaz R, Jenni L (2010) Year-Round Tracking of Small Trans-Saharan Migrants Using Light-Level Geolocators. PLoSONE 5(3): e9566. doi:10.1371/journal.pone.0009566

Baillie S, Bairlein F, Clark J, du Feu C, Fiedler W, Fransson T, Hegelbach J, Juillard R, Karcza Z, Keller LK, Kestenholz M, Schaub M, Spina F (2007) Bird Ringing for Science and Conservation. EURING, The European Union for Bird Ringing. Abächerli Druck AG, Sarnen. 
Bairlein F (1992) Recent prospects on trans-Saharan migration of songbirds. Ibis 134: 4146.

Bairlein F (1995) Manual of field method. European-African songbird migration network. Institut für Vogelforschung Wilhelmshaven.

Bairlein F (1997) Spatio-temporal conservation, ecology and energetics of Western Palaearctic-African songbird migration. Summary report. Institut fuer Vogelforshung Wilhelmshaven.

Bairlein F (1998) The European-African songbird migration network: new challenges for large-scale study of bird migration. Biol. Cons. Fauna 102: 13-27.

Bairlein F (2004) Large-scale networks in bird research in Europe: pitfalls and prospects. Avian Science 3: 49-63

Bairlein F, Nagel R, Bulte M, Voigt CC, Fox JW, Schmaljohann H (2011) Tracks of geolocators support geospatial predictions of wintering quarters made by stable isotope analysis in a migratory songbird. PlosOne, submitted.

Berthold P, Schlenker R (1975) Das "Mettnau-Reit-Illmitz-Programm" - ein langfristiges Vogelfangprogramm der Vogelwarte Radolfzell mit vielfältiger Fragestellung. Vogelwarte 28: $97-123$

Berthold P, Fliege G, Heim G, Querner U, Schlenker R (1991) Autumn migration, resting behaviour, biometry and moult of small birds in central Europe. Vogelwarte 36 special issue: $1-221$

Biebach H. (1990) Strategies of trans-desert migrants. In: Bird migration. Physiology and ecophysiology (ed. E. Gwinner). Berlin, Springer-Verlag.

Busse P (1974) Biometrical methods. Notakti Orn. 15: 114-126.

Busse P, Kania W (1970) The Operation Baltic 1961-1967. Acta Ornithol. 12: 231-267.

Cecere JG (2004) Modalità e strategie di attraversamento del Mediterraneo centro occidentale durante la migrazione primaverile dei passeriformi trans-sahariani. Tesi di Laurea. Facoltà di Scienze Naturali, Università La Sapienza di Roma.

Cecere JG, Matricardi C, Frank B, Imperio S, Spina F, Gargallo G, Barboutis C, Boitani L (2010) Nectar exploitation by songbirds at Mediterranean stopover sites. Ardeola 57: 143157.

Cecere JC, Spina F., Jenni-Eierman S, Boitani L (2011) Nectar: an Energy Drink Used by European Songbirds during Spring Migration. J. Ornithol, in press.

Dolnik VR (1990) Bird migration across arid and mountainous regions of Middle Asia and Kasakhstan. Pp 368-386 in Gwinner, E. (ed.). Bird migration: the physiology and ecophysiology. Springer-Verlag, Berlin. 
Fenech N (1992) Fatal flight: the Maltese obsession with killing birds. Quiller Press, London.

Gill RE, Piersma T, Hufford G, Servrancky R, Riegen DG (2005) Crossing the ultimate ecological barrier: evidence for an 11,000 km-long nostop flight from Alaska t New Zealand and eastern Australia by Bar-tailed Godwits. Condor 107: 1-20.

Goymann W, Spina F, Ferri A, Fusani L (2010) Body fat influences departure from stopover sites in migratory birds: evidence from whole island telemetry. Biol. Lett. 6: 478481.

Grattarola A, Spina F, Pilastro A (1999) Spring migration of the Garder Warbler (Sylvia borin) across the Mediterranean. J. Ornithol. 140: 419-430.

Hepburn JR (1985) La caccia agli uccelli migratori nei Paesi della Comunità Europea. U.N.A.V.I., Firenze.

Hill GE (1989) Late spring arrival and dull nuptial plumage: aggression avoidance by yearling males? Anim. Behav. 37: 665-673.

Hoballah A (1996) Potenzialità di sviluppo nel bacino Mediterraneo. In Montbailliu X. \& Torre A. (eds.). La gestione degli ambienti costieri ed insulari del Mediterraneo. Medmaravis: 395-404.

Jenni L, Jenni-Eiermann S, Spina F, Schwabl H (2000) Regulation of protein breakdown and adrenocortical response to stress in birds during migratory flights. Am. J. Physiol. Regulatory Integrative Comp. Physiol. 278: R1182-R1189.

Kaiser A (1993) A new multi-category classification of subcutaneous fat deposits in songbirds. J. Field Ornithol. 64: 246-255.

Licheri D, Spina F (2002) Biodiversità dell'avifauna italiana: variabilità morfologica nei Passeriformi (Alaudidae-Sylviidae). Biol. Cons. Fauna 112: 1-208.

Licheri D, Spina F (2005) Biodiversità dell'avifauna italiana: variabilità morfologica nei nonPasseriformi. Biol. Cons. Fauna 114: 1-192.

Messineo A, Grattarola A, Spina F (2001). Dieci anni di Progetto Piccole Isole. Biol. Cons. Fauna 106: 1-244.

Newton I (2008) The migration ecology of birds. Academic Press.

Nisbet I.C.T., Drury W.H., Baird J. (1963) Weight-loss durino migration. Part 1: deposition and consumption of fat by the Black-poll Warbler Dendroica striata. Bird-Banding 34: 107138.

Pedrini P, Rossi F, Rizzolli F, Spina F (2008) Le Alpi italiane quale barriera ecologica nel corso della migrazione post-riproduttiva attraverso l'Europa: risultati generali della prima fase del Progetto Alpi (1997-2002). Biol. Cons. Fauna 116: 1-336. 
Pilastro, A., Macchio, S., Massi, A., Montemaggiori A. \& Spina, F. 1998. Spring migration routes of eight trans-Saharan passerines through the central and western Mediterranean: results from a network of insular and coastal ringing sites. Ibis 140: 591-598.

Rubolini D, Spina F, Saino N (2004) Protandry and sexual dimorphism in trans-Saharan migratory birds. Behavioral Ecology Vol. 15 No. 4: 592-601

Rubolini D, Spina F, Saino N (2005) Correlates of timing of spring migration in birds: a comparative study of trans-Saharan migrants. Biological Journal of the Linnean Society: 199-210.

Saino N, Rubolini D, Serra L, Caprioli M, Morganti M, Ambrosini R, Spina F (2010) Sexrelated variation in migration phenology in relation to sexual dimorphism: a test of competing hypotheses for the evolution of protandry. J. Evol. Biol.: 1-12.

Salewski V, Almasi B, Schlageter A (2006) Nectarivory of Palearctic migrants at a stopover site in the Sahara. British Bird, 99: 299-305.

Schaub M, Jenni L (2000) Body mass of six long-distance migrant passerines species alonf the autumn migration route. J. Ornithol. 141: 441-460.

Schaub M, Jenni L (2001) Stopover duration of three warbler species along their autumn migration route. Oecologia 128: 217-227.

Schmaljohann H, Fox J, Bairlein F (2011) Tracking the annual cycle of a high-Arctic songbird migrants suggests a strong endogenously controlled migration strategy. Proc. Royal Soc. London, submitted.

Schwilch R, Mantovani R, Spina F, Jenni L (2001) Nectar consumption of warblers after long-distance flights during spring migration. Ibis 143: 24-32.

Schwilch R, Grattarola A, Spina F, Jenni L (2002) Protein loss during long distance migratory flight in passerine birds: adaptation and constraint. Journal of Experimental Biology 205: 687-695.

Sillet TS, Holmes RT (2002) Variation in survivorship of a migratory songbird throughout its annual cycle. J. Anim. Ecol. 71: 296-308.

Spina F, Massi A, Montemaggiori A, Baccetti N (1993) Spring migration across Central Mediterranean: general results from the 'Progetto Piccole Isole'. Die Vogelwarte 37 (Suppl.): 1-98.

Spina F, Massi A, Montemaggiori A (1994) Back from Africa: who's running ahead? Differential migration of sex and age classes in Palearctic-African spring migrants. Ostrich 65 (Suppl.): 137-150.

Spina F, Licheri D (2003) Biodiversità dell'avifauna italiana: variabilità morfologica nei Passeriformi (Muscicapidae-Emberizidae). Biol. Cons. Fauna 113: 1-180. 
Stutchbury BJM, Tarof SA, Done T, Gow EA, Kramer PM, Tautin J, Fox JW, Afanasyev V (2009) Tracking Long-Distance Songbird Migration by Using Geolocators. Science 323: 896.

Stutchbury BJM, Gow EA, Done T, MacPherson M, Fox JW, Afanasyev V (2010) Effects of post-breeding moult and energetic condition on timing of songbird migration into the tropics, Proceedings of the Royal Society B, 21 July 2010, doi:10.1098/rspb.2010.1220

Tenan S, Spina F (2010) Timing and condition-related affects on recapture probability, mass change and stopover length of spring migrating songbirds on a small Mediterranean island. Ardeola 57(1): 121-132.

Woldhek S (ed.) (1980) Bird killing in the Mediterranean. Intern. Council Bird Preserv. Zeist.

\section{Captions to figures}

Fig. 1: Network of ringing sites: Progetto Piccole Isole, PPI (star indicates Capri, the island with the longest time series of data), Progetto Alpi, PA.

Fig. 2: Capture frequency of Melodious Warbler Hippolais polyglotta and Bonelli's Warbler H. icterina on $21 \mathrm{PPI}$ stations. For each species, frequencies (relative to the total number of migrants, with similar habitat requirements, ringed at that station) were standardised in order to vary between 1 for the station with the highest relative capture frequency of a given species (black) and 0 for the station were the migrant was never captured (grey). From Pilastro et al. 1998.

Fig. 3: Garden Warbler Sylvia borin. Mean length of $8^{\text {th }}$ primary in relation to longitude (open circle $=$ mainland station; filled circle $=$ island station). Line is the least square regression fitted to the points. From Grattarola et al. 1999.

Fig. 4: Garden Warbler Sylvia borin. Mean time (CET) of capture in relation to latitude (open circle $=$ mainland station; filled circle $=$ island station). Line is the least square regression fitted to the points. From Grattarola et al. 1999.

Fig. 5: Mean residual fat load standardised for the flying efficiency (described based on wing length, wing shape and tail length/wing length ratio) of each species, of 28 transSaharan passerine spring migrants at their arrival in southern Europe. Species are grouped accordingly to their preferred wintering habitat. The northernmost latitude at which each habitat can be found in tropical Africa is indicated. From Pilastro \& Spina 1997.

Fig. 6: Collared Flycatcher Ficedula albicollis: annual phenology of birds ringed in Italy years 1982-1999 $(n=1,144)$. Pied Flycatcher Ficedula hypoleuca: annual phenology of birds ringed in Italy years 1982-1999 $(n=46,613)$. Based on 10-day periods. From Spina \& Licheri 2003.

Fig. 7: Barn Swallow Hirundo rustica. Birds ringed in Italy years 1982-1999 $(n=305,318)$ based on 10-day periods. Frequency of fat birds. Fat birds are those scored at least 3 within fat scales ranging between 0 to 5 (Busse 1974) and 0 to 8 (Kaiser 1993). From Licheri \& Spina 2002. 
Fig. 8: Barn Swallow Hirundo rustica. Birds ringed in Italy years 1982-1999 $(n=305,318)$ based on 10-day periods. Average body mass. From Licheri \& Spina 2002. 


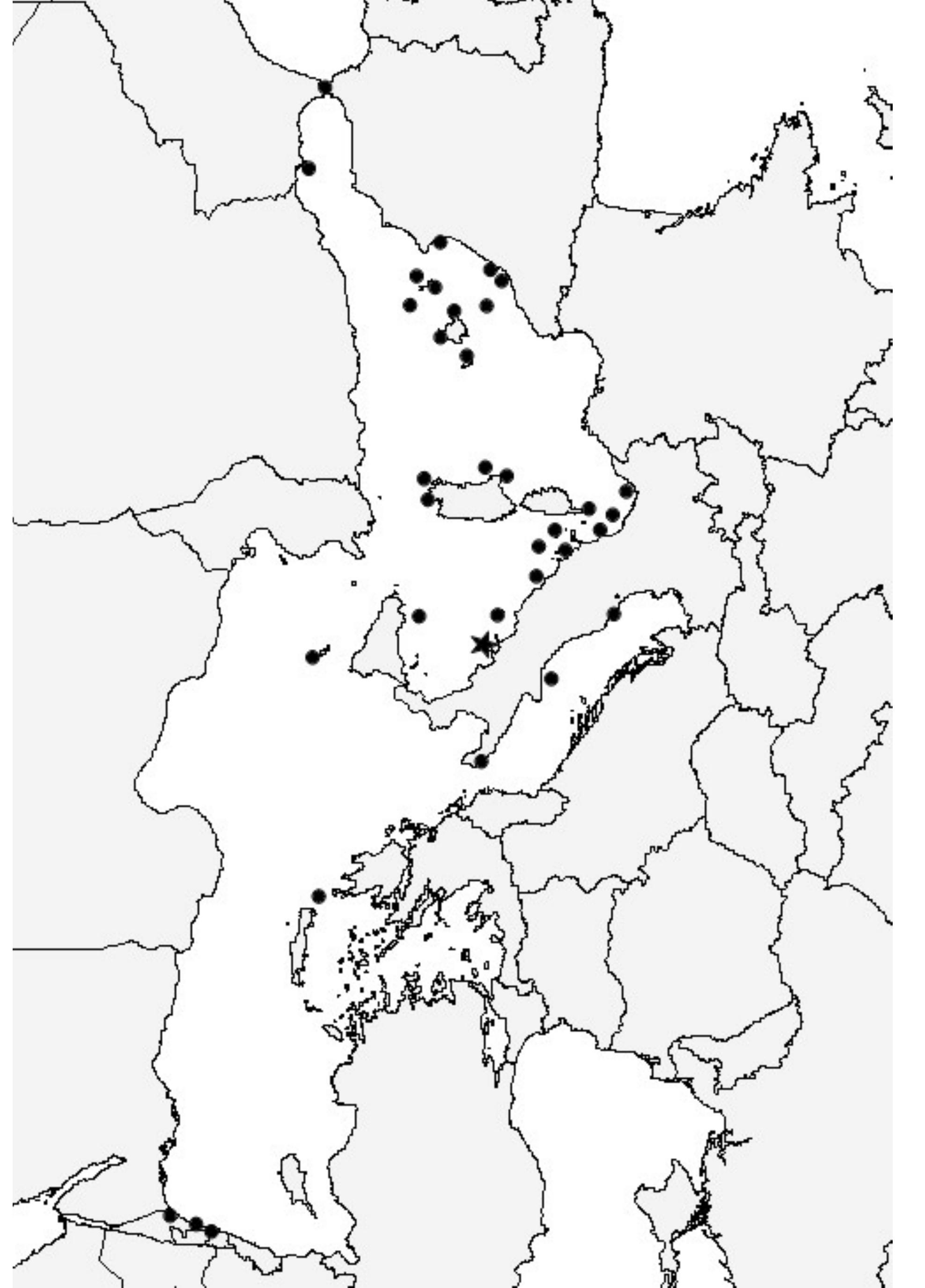



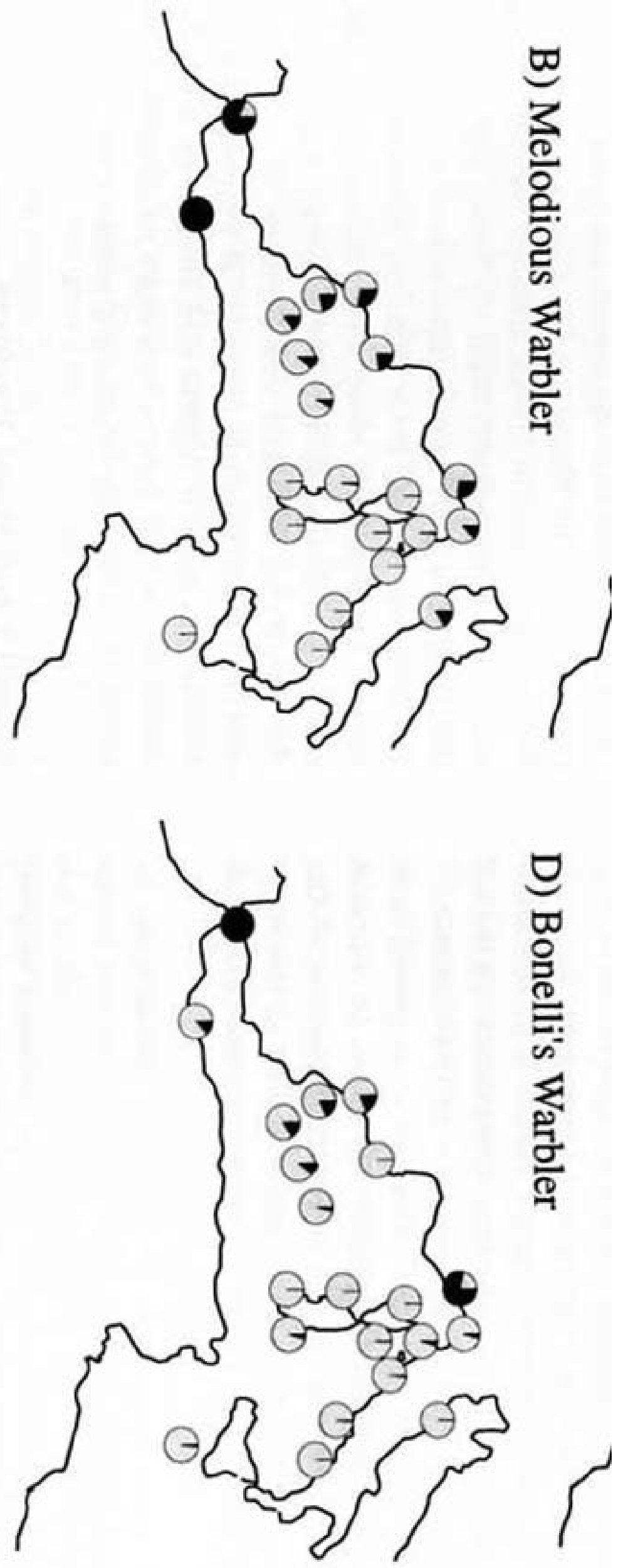
standardized fat load ( \pm SE)

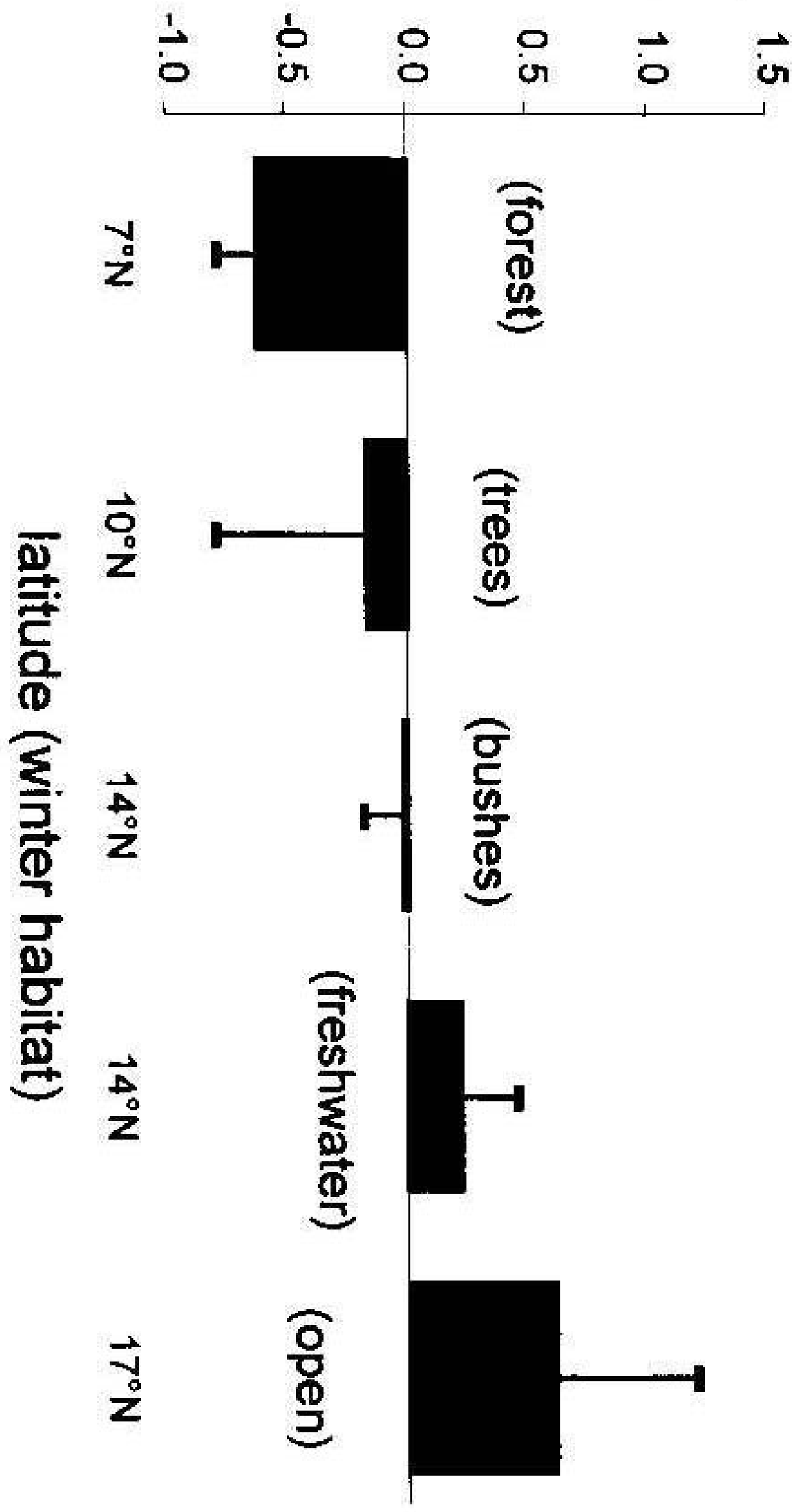




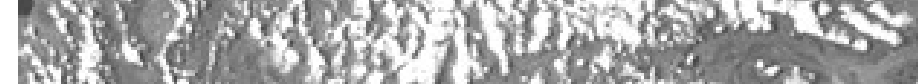

(5)

4.

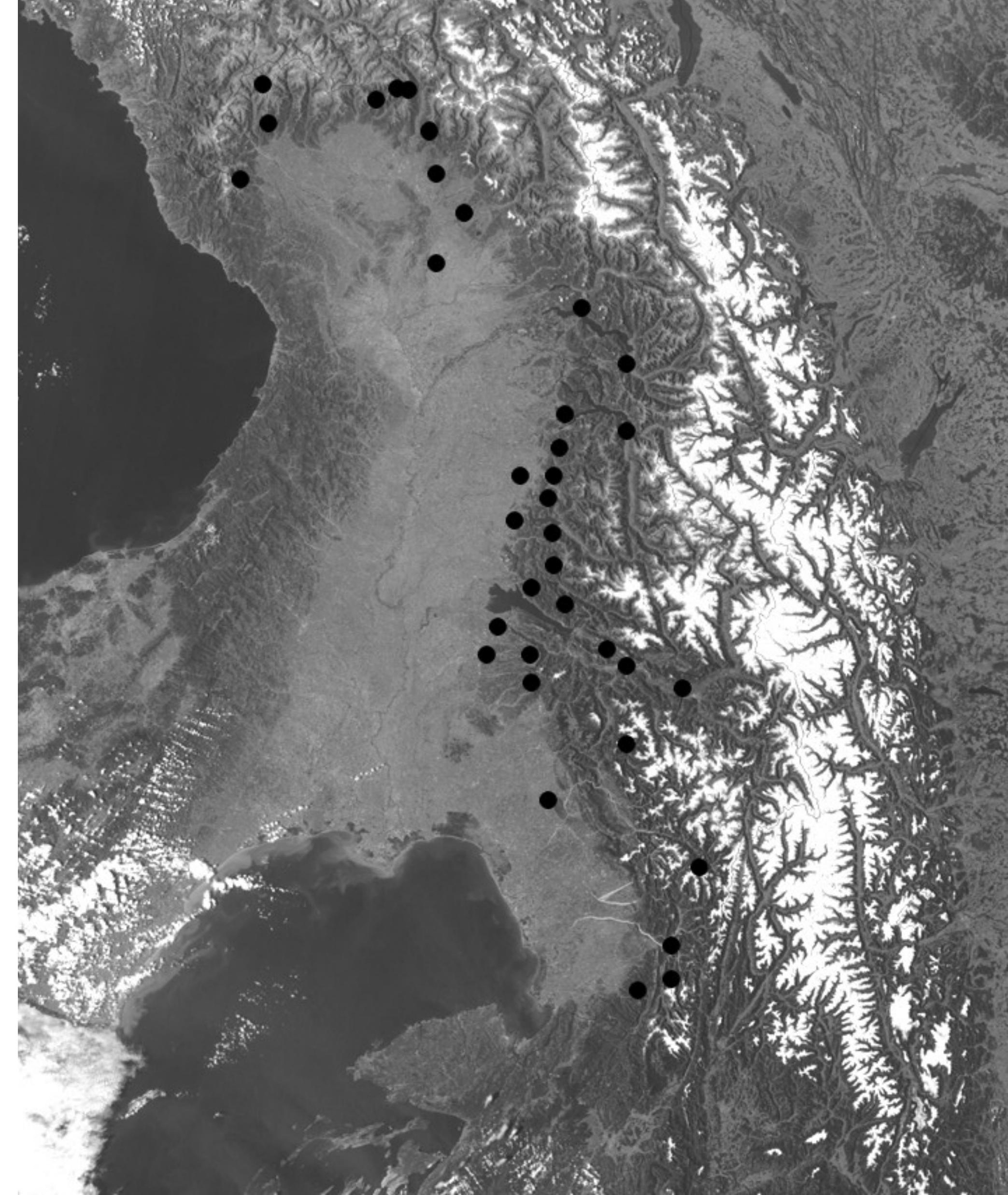


Mean wing length (mm)

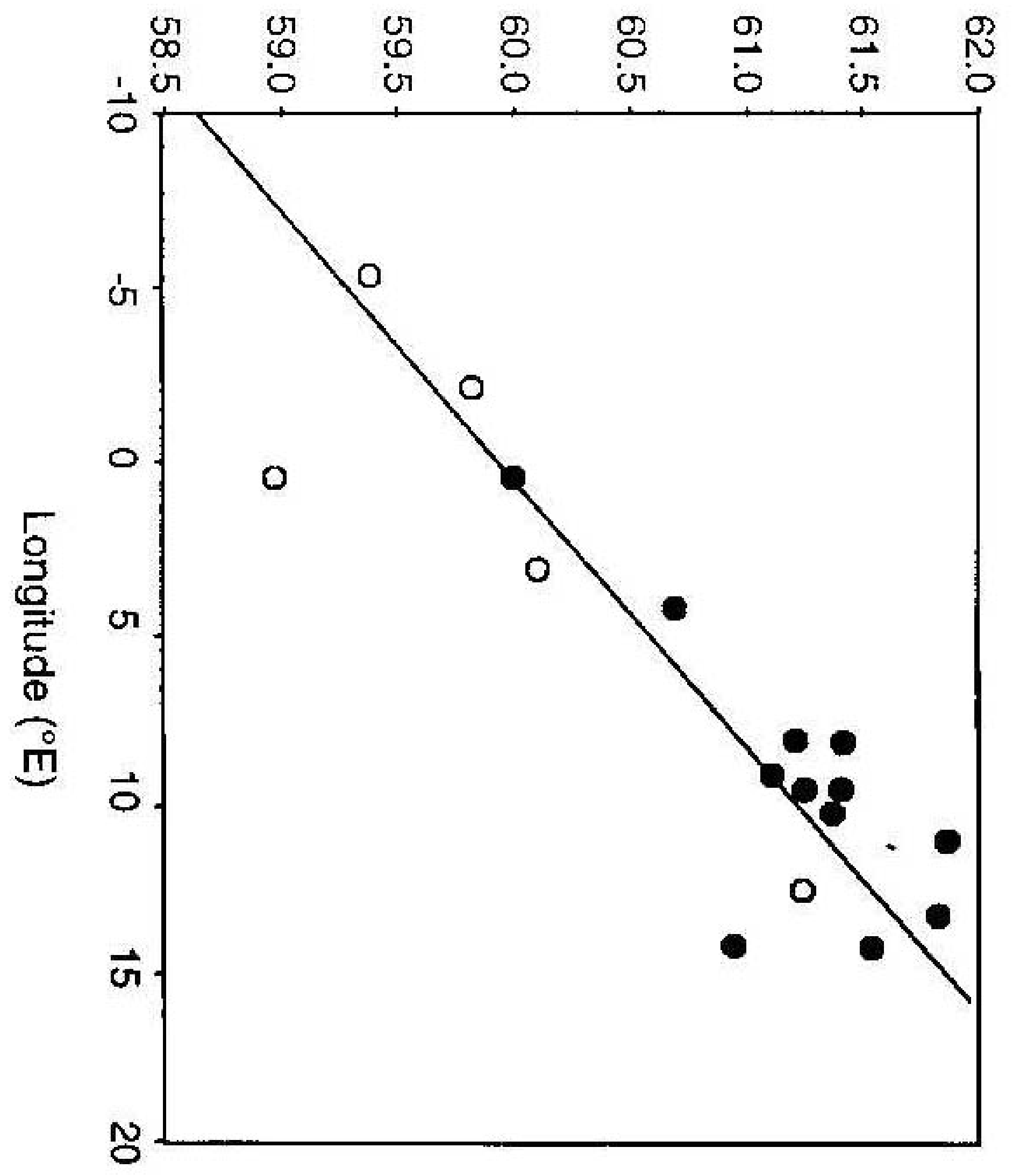


Mean capture time (hours)

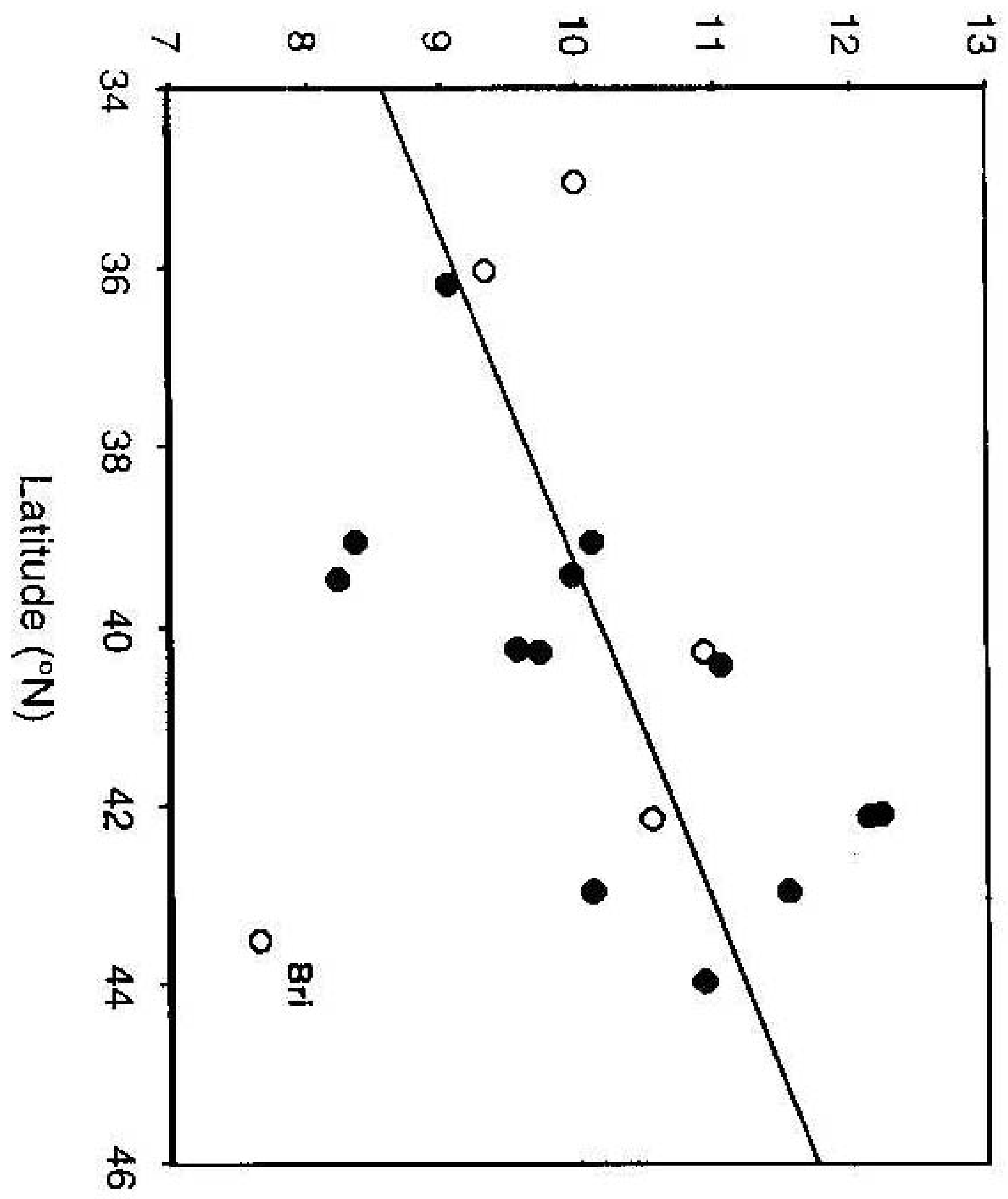




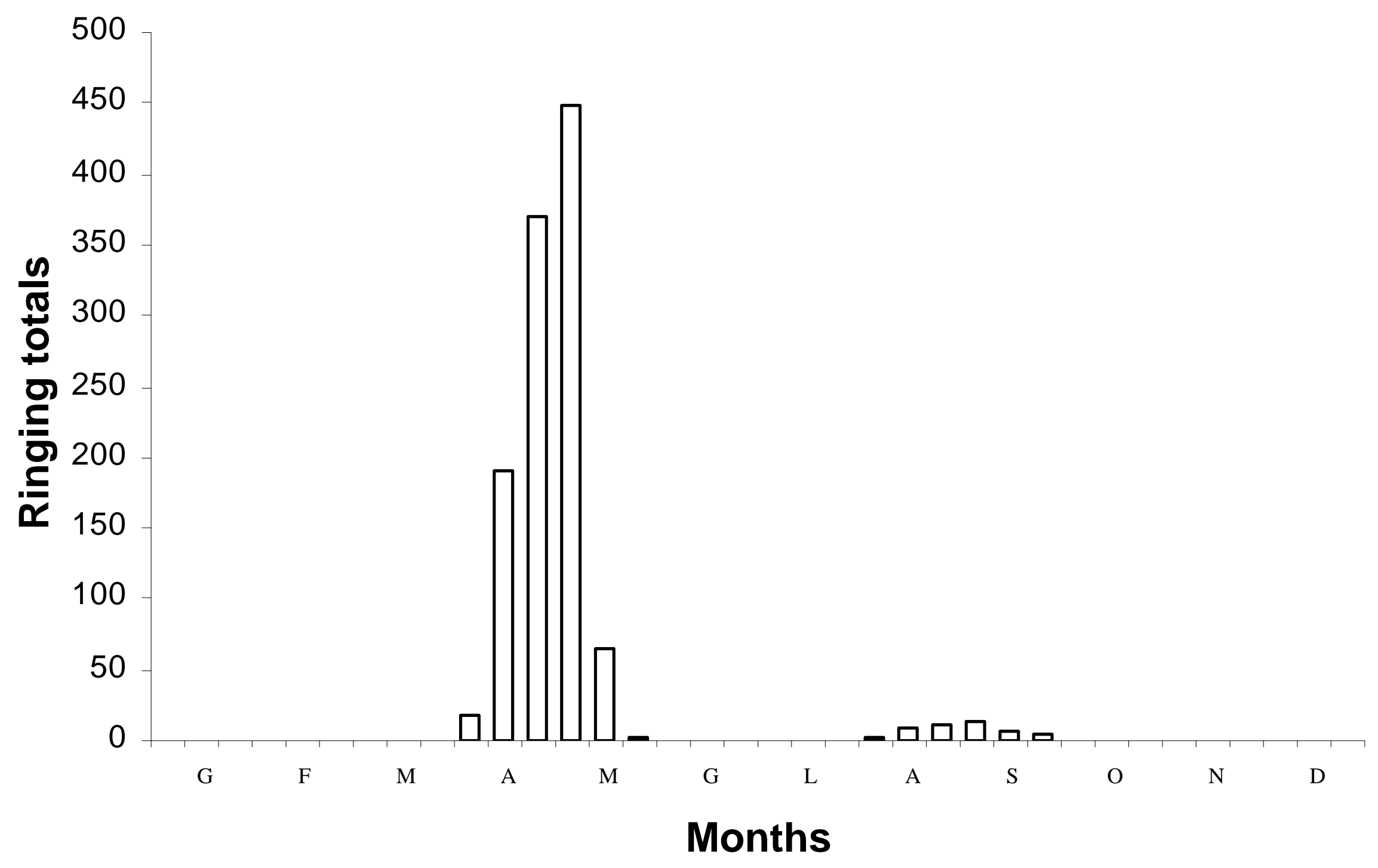




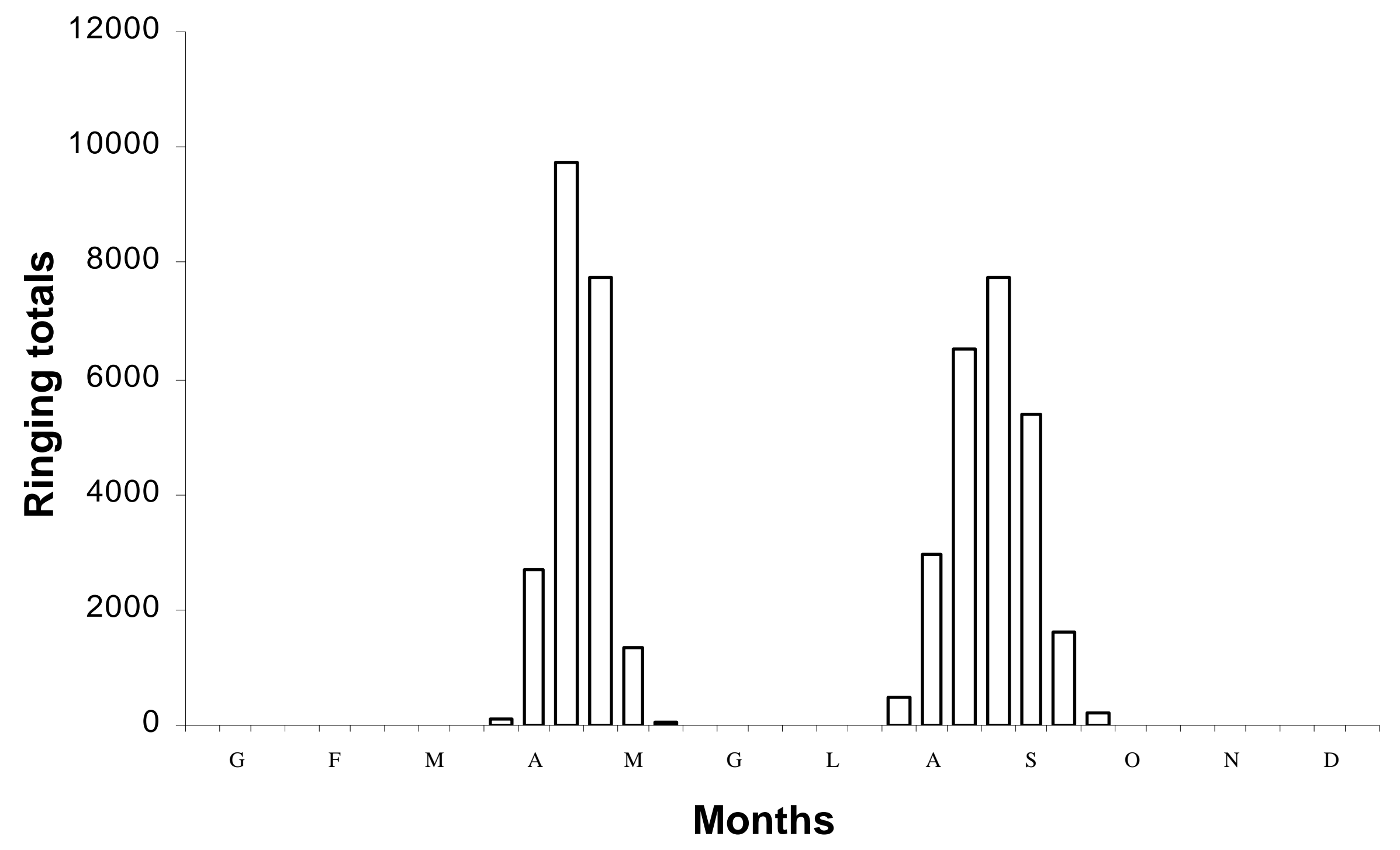




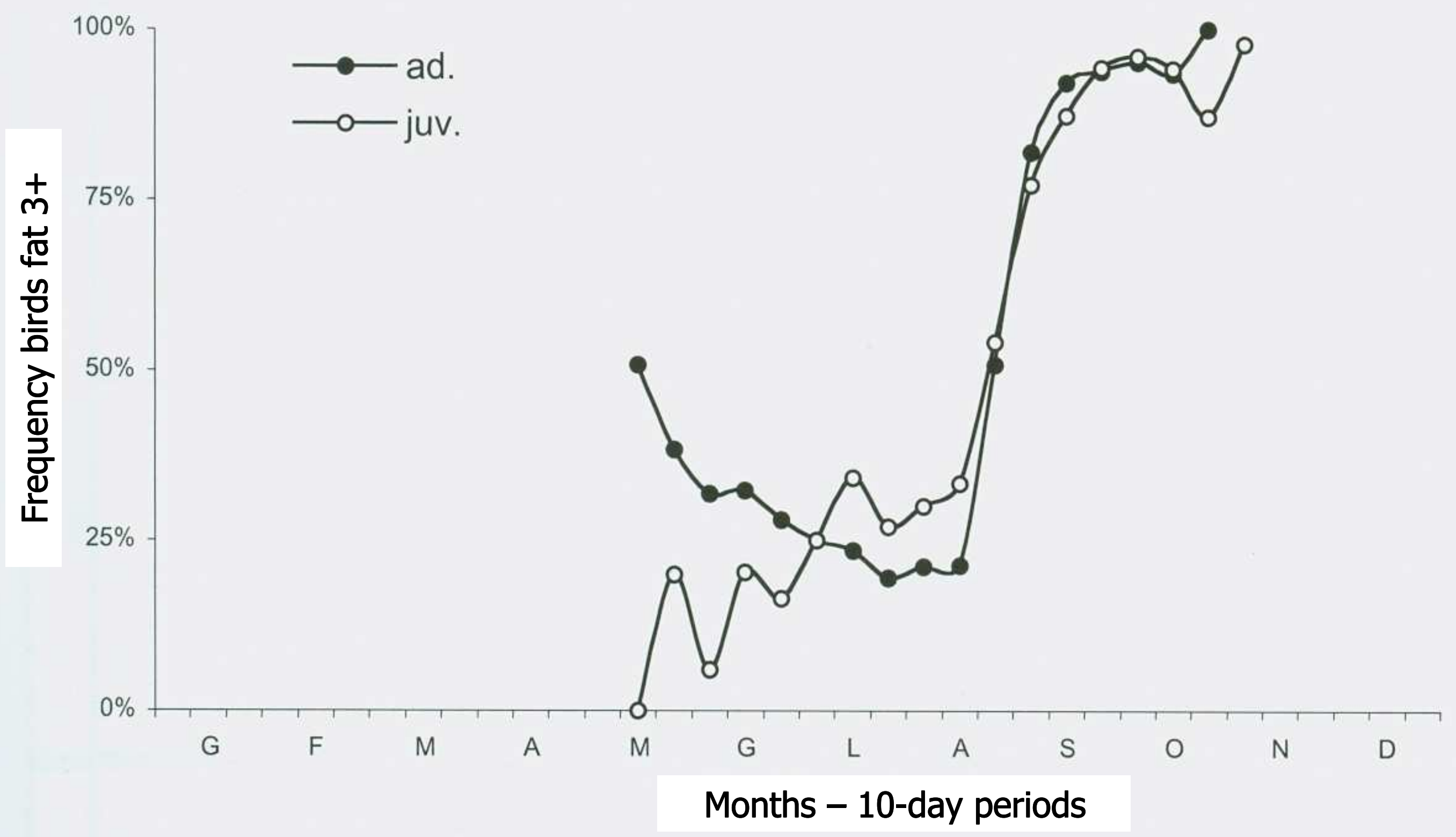




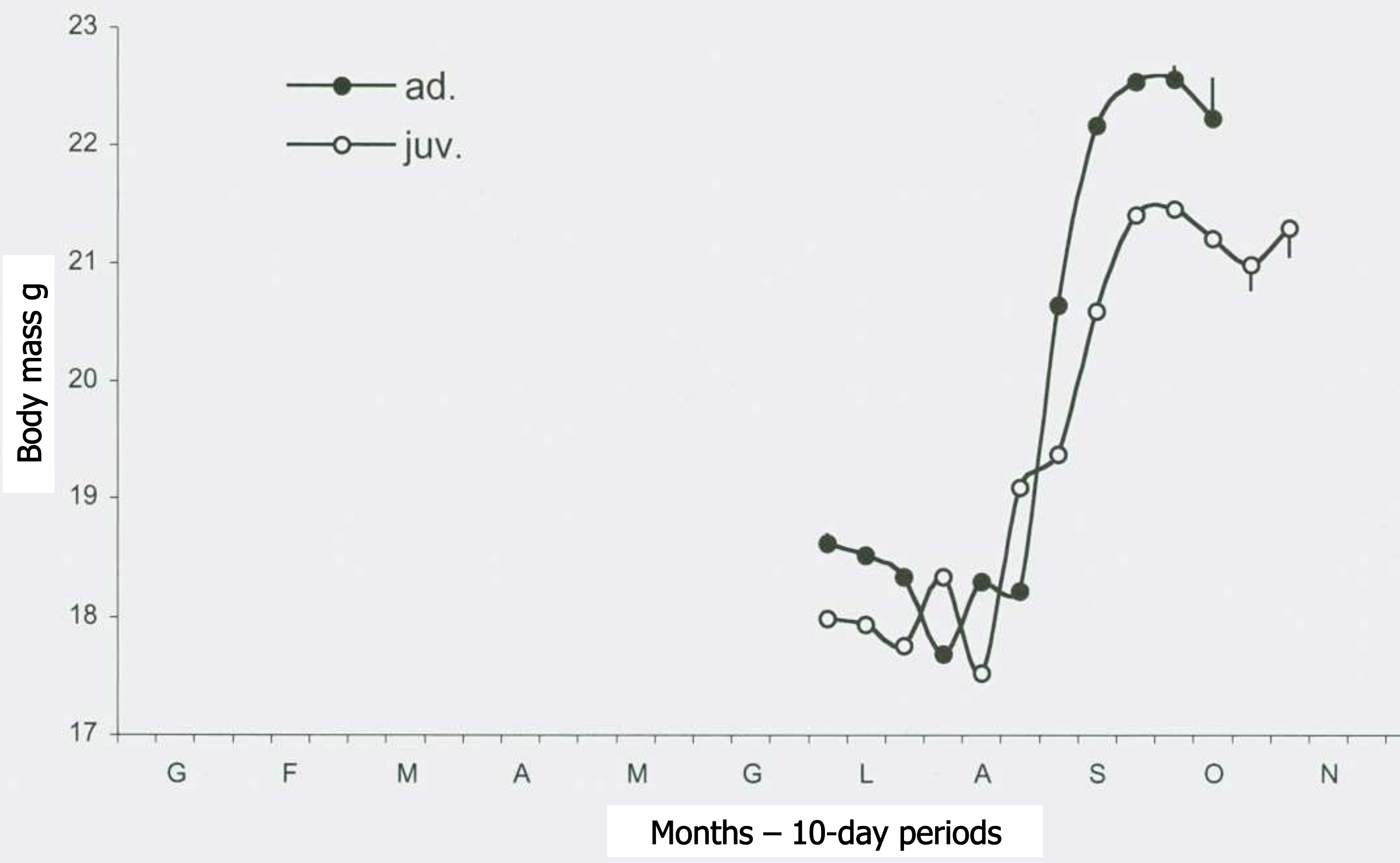

